from healthy donors. Cloning of the mutated gene in a vector for further functional studies.

Results: WES analysis revealed the de novo heterozygous missense variation c.C1132A (p.H378N) in PIM1 gene. This variation was never described in on-line database and was predicted as damaging by various bioinformatic tools. Preliminary functional investigations in fibroblasts showed normal expression of Pim1, but higher phosphorylation of BAD protein was measured in cells from the patient. Moreover, PBMC from the patient displayed a lower sensitivity to the PIM inhibitor PIM447. RNAseq showed an altered expression profile in genes involved in the extracellular matrix organization.

Conclusion: PIM1 is an oncogene that encodes a protein kinase and, indeed, somatic gain of function mutations can be found in cancers. Preliminary data obtained from our patient suggest a gain of function effect of the p.H378N variant. The lymphoproliferative disorder may be sustained by the anti-apoptotic action of phosphorylated BAD. Recent data correlated hyperactive PIM1 in tumors with high degree of inflammatory infiltration accompanied by NFAT and mTOR activation and IL6 expression. A role of this cytokine also in our patient was coherent with a good clinical response to a treatment with tocilizumab, targeting IL-6.

Although these results are supportive of a role of mutated PIM1 in the observed phenotype, we cannot still claim that this is causative of a novel syndrome. The detection of further cases and functional studies on cells transfected with mutated PIM1 will help shedding more light on this inflammatory and lymphoproliferative disorder.

Disclosure of Interests: None declared

DOI: 10.1136/annrheumdis-2019-eular.8060

\section{AB1106 PREVALENCE AND EPIDEMIOLOGY OF FAMILIAL MEDITERRANEAN FEVER AND TUMOR NECROSIS FACTORRECEPTOR-ASSOCIATED PERIODIC SYNDROME: RESULTS FROM AN ITALIAN CENTER}

Rossella Talotta $^{1}$, Lorena Mosca ${ }^{2}$, Francesco Rucci ${ }^{1}$, Antonio Brucato ${ }^{3}$, Fabiola Atzeni ${ }^{4}$, Carlo Federico Perno ${ }^{5}$, Francesco Scaglione ${ }^{6}$, Ugo Cavallari ${ }^{2}$. ${ }^{1}$ University of Milan, Postgraduate School of Clinical Pharmacology and Toxicology, Milan, Italy; ${ }^{2}$ ASST Grande Ospedale Metropolitano Niguarda, Medical Genetics Unit, Department of Laboratory Medicine, Milan, Italy; ${ }^{3}$ Papa Giovanni XXIII Hospital, Internal Medicine Unit, Bergamo, Italy; ${ }^{4}$ University of Messina, Rheumatology Unit, Messina, Italy; ${ }^{5}$ ASST Grande Ospedale Metropolitano Niguarda, Chemical-Clinical Analysis and Microbiology, Department of Laboratory Medicine, Milan, Italy; ${ }^{6}$ University of Milan, Department of Oncology and OncoHematology, Milan, Italy

Background: Familial Mediterranean fever (FMF) and tumor necrosis factor (TNF) receptor-associated periodic syndrome (TRAPS) represent two forms of periodic monogenic autoinflammatory diseases, characterized by recurrent and auto-limiting attacks of fever and systemic inflammation. Both the diseases are due to the aberrant activation of inflammasome platforms. Several variants in the Mediterranean Fever (MEFV) gene and TNF Receptor Superfamily Member 1A (TNFRS1A) gene are respectively at the basis of FMF and TRAPS.

Objectives: The aim of this study is to report the genotype and phenotype prevalence of a cohort of patients referring to our laboratory with a suspicious diagnosis of FMF or TRAPS.

Methods: We retrospectively collected genetic and demographic data of patients undergoing MEFV (NM_000243) and TNFRS1A (NM_001065) genetic test at our laboratory. Both genes were analysed by direct sequencing on both strands. Data were statistically analysed for descriptive and inferential purposes.

Results: A total of 168 cases were collected, most of which were Caucasian subjects $(88.0 \%)$. The most common clinical manifestation was periodic fever, occurring in 121 cases, with musculoskeletal, intestinal and cutaneous symptoms, polyserositis and lymphadenopathy occurring at variable rates. Demographic and clinical characteristics are resumed in tab.1. MEFV genotyping, performed in 159 patients, identified 8 different pathogenic variants (p.Phe479Leu, p.Met680lle, p.Met694Val, p.Met694lle, p. Lys695Arg, p.Val726Ala, p.Ala744Ser, p. Arg761His), associated with different geographic provenience and symptoms (tab.2, 4).
Analysis of TNFRS1A gene in 80 subjects revealed the presence of the pathogenic variant p.Cys102Tyr in 3 patients $(3.75 \%)$; tab.3, 5 .

According to Eurofever scoring system, the MEFV variant p.Ala744Ser was significantly associated to the likelihood of having FMF and to the severity of the disease. A higher prevalence of MEFV pathogenic variants was observed in Egyptians and patients living in Southern Italy.

\begin{tabular}{|l|l|}
\hline Patients n. 168 & $39.9 \pm 18.0$ \\
\hline Age, years (mean \pm SD) & $25.8 \pm 16.3$ \\
\hline $\begin{array}{l}\text { Age at disease onset, years } \\
\text { (mean } \pm \text { SD) }\end{array}$ & $94(56.0 \%) / 74(44.0 \%)$ \\
\hline Gender [females/males; n. $(\%)]$ & $121(72.0 \%)$ \\
\hline Periodic fever, n.(\%) & $72(42.9 \%)$ \\
\hline $\begin{array}{l}\text { Musculoskeletal symptoms, } \\
\text { n.(\%) }\end{array}$ & $14(8.3 \%)$ \\
\hline Cutaneous rash, n.(\%) & $4(2.4 \%)$ \\
\hline Eye involvement, n.(\%) & $19(11.3 \%)$ \\
\hline Oral aphtosis, n.(\%) & $4(2.4 \%)$ \\
\hline Spleen enlargement, n.(\%) & $6(3.6 \%)$ \\
\hline Hepatomegaly, n.(\%) & $34(20.2 \%)$ \\
\hline Lymphoadenopathy, n.(\%) & $77(45.8 \%)$ \\
\hline Intestinal symptoms, n. $(\%)$ & $39(23.2 \%)$ \\
\hline Pericarditis, n.(\%) & $10(6.0 \%)$ \\
\hline Peritonitis, n.(\%) & $22(13.1 \%)$ \\
\hline Pleuritis, n.(\%) & $23(13.7 \%)$ \\
\hline Pharyngodynia, n.(\%) & $22(13.1 \%)$ \\
\hline Familial history, n.(\%) & $27(16.1 \%)$ \\
\hline NSAIDs, n.(\%) & $36(21.4 \%)$ \\
\hline Steroids, n.(\%) & $35(20.8 \%)$ \\
\hline Colchicine, n.(\%) & $12(7.1 \%)$ \\
\hline Immunosuppressants, n.(\%) & \\
\hline
\end{tabular}

Table 1. Demographic characteristics of the whole cohort of patients examined.
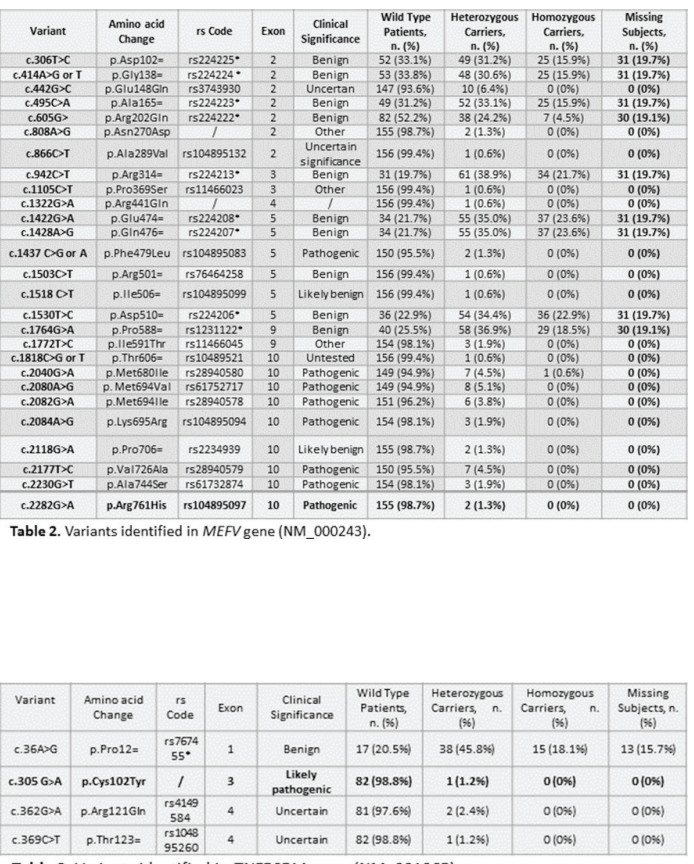

Table 3. Variants identified in TNFRSF1A gene (NM_001065) 


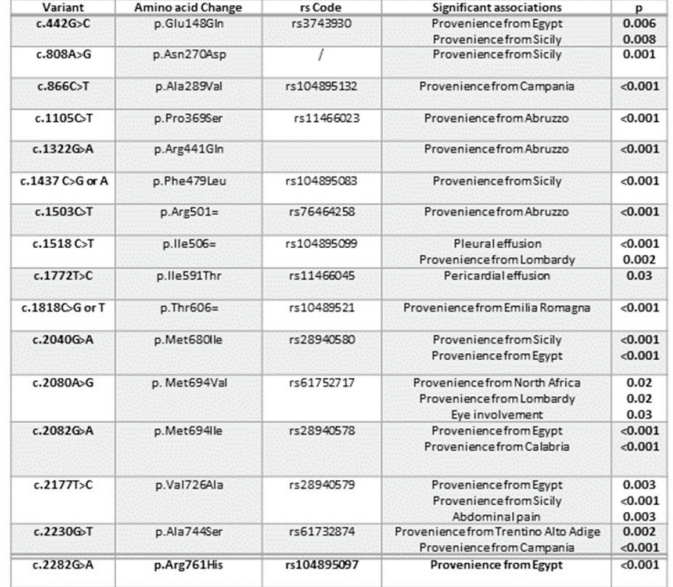

Table 4. Significant associations between pathogenic or uncertain significance variants and geographical provenience and clinical data of MEFV gene-tested patients.

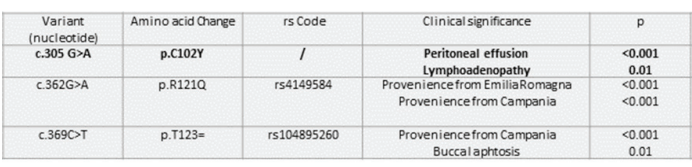

Table 5. Significant associations between pathogenic or uncertain significance variants and geographical provenience and clinical data of TNFRSF1A gene-tested patients.

Conclusion: Our data report MEFV and TNFRS1A genotypes identified in a cohort of patients referring to an Italian center, affected by periodic fever and other systemic symptoms. Only the MEFV variant p.Ala744Ser appeared to be significantly correlated with the Eurofever classification score.

\section{REFERENCES}

[1] Vitale A, Rigante D, Lucherini OM, De Palma A, Orlando I, Gentileschi S, Sota J, Simpatico A, Fabiani C, Galeazzi M, Frediani B, Cantarini L. The diagnostic evaluation of patients with a suspected hereditary periodic fever syndrome: experience from a referral center in Italy. Intern Emerg Med. 2017;12(5):605-611.

[2] Federici S, Sormani MP, Ozen S, Lachmann HJ, Amaryan G, Woo P, Koné-Paut I, Dewarrat N, Cantarini L, Insalaco A, Uziel Y, Rigante D, Quartier P, Demirkaya E, Herlin T, Meini A, Fabio G, Kallinich T, Martino S, Butbul AY, Olivieri A, Kuemmerle-Deschner J, Neven B, Simon A, Ozdogan H, Touitou I, Frenkel J, Hofer M, Martini A, Ruperto N, Gattorno M; Paediatric Rheumatology International Trials Organisation (PRINTO) and Eurofever Project. Evidence-based provisional clinical classification criteria for autoinflammatory periodic fevers. Ann Rheum Dis. 2015;74 (5):799-805

Disclosure of Interests: None declared

DOI: 10.1136/annrheumdis-2019-eular.1920

\section{AB1107 COMPLEMENTARY AND ALTERNATIVE MEDICINE USAGE IN PATIENTS WITH FAMILIAL MEDITERRANEAN FEVER}

Seda Colak ${ }^{1}$, Emre Tekgoz ${ }^{1}$, Fatma IIlknur Cinar ${ }^{2}$, Sedat Yilmaz ${ }^{1}$, Muhammet Çınar ${ }^{1} .{ }^{1}$ University of Health Sciences, Gulhane Faculty of Medicine, Department of Internal Medicine, Division of Rheumatology, Ankara, Turkey; ${ }^{2}$ University of Health Sciences, Gulhane Faculty of Nursing, Department of Internal Medicine Nursing, Ankara, Turkey

Background: Familial Mediterranean Fever (FMF) is the most common hereditary, chronic autoinflammatory disease. Colchicine is the mainstay of the treatment, which reduces frequency of attacks and amyloidosis risk. Complementary and alternative medicine (CAM) therapies can be a nonmainstream treatment choice in chronic diseases. Frequency of use of CAM therapies among patients with FMF is not established yet.
Objectives: In the current study we aimed to identify the prevalence of the patients using CAM therapies and the factors associated with CAM usage among the patients with FMF.

Methods: One hundred and sixty-five patients were included in the study. Data regarding demographic, social and clinical characteristics were obtained from the patients. The patients were asked whether they were using any type of CAM and if they had suffered harm and/or benefit. The treatment adherence of the patients was assessed using by Morisky Green Levine Scale (MGLS). The Beliefs About Medicines Questionnaire (BMQ-T) was used to assess patient's beliefs about medicines.

Results: Fifty-six (33.9\%) patients declared to use at least one CAM The mean age of the patients was $34.1 \pm 12.7$ years and the mean disease duration was $16.8 \pm 10.8$ years. The mean dose of colchicine was $1.4 \pm 0.4 \mathrm{mg} /$ day. Patients with concomitant disease and positive history of FMF in relatives had higher rates of using of CAM ( $p=0.011$ and $p=0.014$ respectively). There was no statistically significance between age, sex, marital, socioeconomic and working status, difficulty of access to the treatment center, dose of colchicine, adverse events related to colchicine, attack frequency and disease severity of the patients and frequency of CAM using ( $p>0.05)$. The most frequently chosen types of CAM modalities were massage therapy $(12.1 \%)$, imagining $(9.7 \%)$, relaxation techniques $(9.1 \%)$, cupping $(9.1 \%)$ and natural products $(9.1 \%)$. It is found that $42(75.0 \%)$ of patients reported that they have suffered benefit from CAM. The mean duration of the using of CAM was $7.9 \pm 6.4$ years.

According to the BMQ-T, there was higher rate of concern about colchicine among patients that were using CAM $(p=0.035)$ (Table 1). There was no statistically significance between compliance with colchicine treatment and using of CAM $(\mathrm{p}=0.313)$

Abstract AB1107 Table 1. Comparison of Beliefs about Medicines Questionnaire Scale of patients according to the use of CAM

\begin{tabular}{|c|c|c|c|c|}
\hline Variable & $\begin{array}{l}\text { CAM user } \\
(n=56)\end{array}$ & $\begin{array}{l}\text { CAM non-user } \\
(n=109)\end{array}$ & test & $p$ \\
\hline & $\begin{array}{l}\text { Median (25th-75th } \\
\text { percentile) }\end{array}$ & $\begin{array}{l}\text { Median (25th-75th } \\
\text { percentile) }\end{array}$ & & \\
\hline $\begin{array}{l}\text { BMQ-T-Specific } \\
\text { Necessity }\end{array}$ & $4.0(3.6-4.6)$ & $4.0(3.3-4.6)$ & $\underset{\mathrm{a}}{-0.410}$ & 0.682 \\
\hline $\begin{array}{l}\text { BMQ-T-Specific } \\
\text { Concerns }\end{array}$ & $3.2(2.6-3.8)$ & $2.8(2.4-3.6)$ & $\underset{\mathrm{a}}{-2.110}$ & 0.035 \\
\hline $\begin{array}{l}\text { BMQ-T-General } \\
\text { Overuse }\end{array}$ & $2.5(2.3-3.3)$ & $2.5(2.0-3.1)$ & $-0.675^{a}$ & 0.500 \\
\hline $\begin{array}{l}\text { BMQ-T-General } \\
\text { Harm }\end{array}$ & $2.4(2.0-3.0)$ & $2.3(2.0-3.0)$ & $\underset{a}{-0.858}$ & 0.391 \\
\hline
\end{tabular}

$C A M$ complementary and alternative medicine, $B M Q-T B e l i e f s$ about Medicines

Questionnaire Turkish translation, a Mann-Whitney $U$ test:

Conclusion: Colchicine is the gold standard of treatment because of the known effect of colchicine treatment on the severity and frequency of FMF attacks and the risk of development of amyloidosis. Approximately one third of patients with FMF were using at least one of the CAM modalities in the current study. Concerns about colchicine treatment may have increased the tendency to use CAM therapies. On the other hand, patients should be informed that CAM therapies should not be an alternative to colchicine.

Disclosure of Interests: None declared

DOI: 10.1136/annrheumdis-2019-eular.3717

\section{AB1108 COEXISTENCE OF SARCOIDOSIS AND CHRONIC INFLAMMATORY RHEUMATIC DISEASES}

Marta Valls Roc ${ }^{1}$, Meritxell Sallés Lizarzaburu ${ }^{2}$, Sonia Mínguez Blasco ${ }^{2}$, Elisabet Garcia Casares $^{3}$, Elena Riera Alonso ${ }^{4}$, Vera Ortiz-Santamaria ${ }^{5}$, Clara Sanguesa ${ }^{6}$, Alejandro Olive ${ }^{6} .{ }^{1}$ Hospital de Figueres, Rheumatology, Figueres, Spain; ${ }^{2}$ Althaia, Xarxa Assistencial Universitària de Manresa, Rheumatology, Manresa, Spain; ${ }^{3}$ Hospital Mollet, Mollet del Vallès, Spain; ${ }^{4}$ Mútua Terrassa University Hospital, Terrassa, Spain; ${ }^{5}$ Hospital General de Granollers, Granollers, Spain; ${ }^{6}$ Hospital Germans Trias i Pujol, Badalona, Spain

Background: Sarcoidosis is a systemic granulomatous disease of unknown etiology, mediated by Th1 lymphocytes, characterized by bilateral hilar adenopathies, pulmonary infiltrates, ocular, articular and cutaneous involvement and histologically by noncaseating granulomas. Sarcoidosis can simulate many chronic rheumatic diseases but can also coexist with them, so there are doubts about whether there is a true association or is incidental. Likewise, the occurrence of sarcoidosis has been described as a paradoxical effect during treatment with biological drugs, especially with tumor necrosis factor antagonists possibly due to a dysregulation in the compensatory proinflammatory cascade related of TNF blockade. The association between sarcoidosis and Sjögren's syndrome, systemic lupus 